\title{
Adaptive proximal scaphoid implant (APSI): a systematic review of the literature
}

\author{
Giuseppe Mosillo', Morena Anna Basso', Giovanni Balato', Alessio Bernasconi', Antonio Coviello², \\ Federico Tamborini ${ }^{3}$, Andrea Poggetti ${ }^{4}$, Francesco Smeraglia ${ }^{1}$ \\ 1 Department of Orthopaedic Surgery, "Federico II" University, Via S. Pansini 5, bd. 12, 80131, Naples, Italy, ${ }^{2}$ Department of Anesthesia, "Federico II" \\ University, Via S. Pansini 5, bd. 12, 80131, Naples, Italy, ${ }^{3}$ Hand and Reconstructive Microsurgery Unit, Azienda Ospedaliera Careggi, Florence, Italy, 4 \\ Plastic and Reconstructive Surgery, University of Insubria, Varese, Italy \\ Keywords: SNAC, scaphoid, pyrocarbon, implant, wrist \\ https://doi.org/10.52965/001c.30721
}

\section{Orthopedic Reviews}

Vol. 14, Issue 1, 2022

\begin{abstract}
Scapholunate advanced collapse collapse (SLAC) is a challenging topic for hand surgeons. The adaptative proximal scaphoid implant (APSI) (Bioprofile-Tornier) is a pyrocarbon ovoid shaped interpositional implant, that allows adaptive mobility during motion. The aim of this systematic review is to analyze the clinical and radiological outcomes of APSI implants and possible complications. We performed a literature search combining the following key-words: “APSI”, "Scaphoid’s proximal pole”, "implant”, “scaphoid avascular necrosis", "SLAC”, “SNAC”, "pyrocarbon”, "prosthesis”, and "spacer” with no limitations for year of publication. We selected seven studies considered relevant to our systematic review. All studies described an improvement in the grip strength and the flexion extension arch compared to pre-operative values. The percentage of patients who reported progression of osteoarthritis (OA) with APSI was $17.3 \%$, and implant's mobilization has a rate $5.1 \%(8 / 156)$. In conclusion the APSI implant is a reliable alternative for the treatment of SNAC wrist and SLAC wrist.
\end{abstract}

\section{INTRODUCTION}

Scaphoid proximal pole nonunion treatment is a challenging topic for hand surgeons. The natural evolution will lead to osteoarthritis (OA) and scaphoid nonunion advanced collapse (SNAC). ${ }^{1}$ Similarly, scapholunate instability leads to carpal malalignment and subsequently to osteoarthritic changes of the radio-carpal joint (scapholunate advanced collapse SLAC). ${ }^{2}$ When it is not anymore possible to reconstruct the necrotic pole or to correct the carpal malalignment, salvage surgical procedures are indicated; procedures such as proximal row corpectomy (PRC), four corner fusion (4CF), or total wrist fusion (TWF) significantly decrease pain but also reduce the ROM. ${ }^{3}$

The adaptative proximal scaphoid implant (APSI) is a hydrocarbon ovoid-shaped interpositional implant that allows adaptive mobility during motion. ${ }^{4}$

The Pyrocarbon has good compatibility with joint cartilage and bone, a modulus of elasticity similar to bone minimizing stress shielding effects and resorption. 5,6 The implant is designed with two radii of curvature: in the frontal plane, the smaller radius of curvature corresponds to the scaphoid fossa, and the larger radius of curvature is directed anteroposteriorly to the transverse plane. These two axes of the implant make it adaptable to the kinematics of the wrist. ${ }^{7}$ The APSI implant is an attractive solution because it is minimally invasive and does not "burn bridges" for salvage procedures such as PRC or $4 \mathrm{CF}$. The implant can avoid a proximal row collapse, maintain carpal kinematics, and it is believed to prevent the progression of osteoarthritis. ${ }^{4}$

A systematic review was conducted to analyze the clinical and radiological outcomes of APSI implants and possible complications for evaluating if it is a safe and reliable alternative for treating SNAC and SLAC wrist.

\section{METHODS}

\section{SEARCH STRATEGY AND LITERATURE SEARCH}

A systematic review of the literature was conducted according to the Preferred Reporting Items for Systematic Reviews and Meta-Analyses (PRISMA) guidelines. ${ }^{8}$ The two investigators (FS, GM) independently performed the literature search. The literature search was conducted in the following databases: Medline (PubMed), Web of Science, and Scopus were accessed on the $30^{\text {th }}$ of October 2020. The following keywords were used in combination: APSI, scaphoid proximal pole, implant, scaphoid avascular necrosis, SLAC, SNAC, pyrocarbon, prosthesis, and spacer with no limitations for the year of publication. Two authors independently assessed the abstract of each publication. Article full-text was accessed for all the relevant abstracts. If the full text was not available, this warranted the exclusion from the study. The bibliography of each full-text article was also retrieved to identify additional studies. 


\section{ELIGIBILITY CRITERIA}

All the studies reported data of patients undergoing the APSI procedure for SNAC and SLAC wrist. According to the authors' language capabilities, English, Spanish, Italian, and French articles were considered. Either prospective or retrospective clinical studies were considered. Only studies published in a peer-reviewed fashion were eligible.

\section{METHODOLOGICAL QUALITY ASSESSMENT}

The two investigators (FS, GM) independently evaluated each study according to the Coleman Methodological Score (CMS). ${ }^{9-11}$ The CMS score is highly reliable, and it is widely used to assess the methodological quality of systematic reviews and meta-analyses. With this score, we analyze several characteristics of the included papers: study size, follow-up duration, surgical approach, type of study, description of surgical technique, rehabilitation, and complications. Further outcome criteria assessment, the procedure of assessing outcomes, and the subject selection process were also evaluated. CMS scores ranks from 0 (poor quality) to 100 (excellent quality), with values $>60$ considered satisfactory.

\section{OUTCOMES OF INTEREST}

Data extraction was performed by two independent authors (FS, GM). The following demographic data were extracted: number of patients, sex, gender, mean age, follow-up duration. The following outcomes of interest were extracted: Disabilities of the Arm, Shoulder, and Hand (DASH) questionnaire, a $10-\mathrm{cm}$ Visual Analogical Scale (VAS), the Mayo Wrist Score (MWS), the Patient-Rated Wrist Evaluation (PRWEB), grip strength and Range of Motion (ROM) (flexion-extension arch), return to work, carpal misalignment, osteoarthritis progression, and complications.

\section{RESULTS}

\section{SEARCH RESULTS}

The literature search resulted in 164 articles. Of these, 144 were excluded based on the title because not inherent to our review. A further 13 articles were excluded after the reading of the abstract. Finally, seven studies were considered for the present study (Figure 1).

\section{METHODOLOGICAL QUALITY ASSESSMENT}

The CMS evidenced some limitations and points of strength of the present study. Study size and follow-up duration were poor. The surgical approach, surgical technique, and rehabilitation were well described. Complications were thoroughly discussed in most articles. Outcome measures and related timing of assessment were often defined, reporting moderate reliability. The procedure assessing outcomes and the subject selection processes were often biased and not satisfactorily described. The mean CMS was 60 (52 to 71), indicating a satisfying quality. The CMS is shown in Table 1.

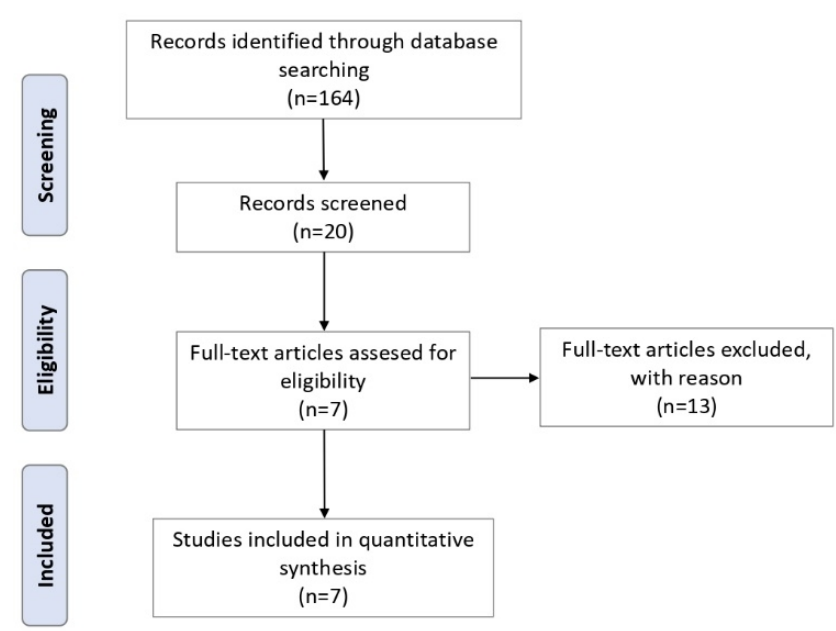

Figure 1. Flow-chart of the literature search

\section{PATIENT DEMOGRAPHIC}

Data from 156 procedures were retrieved. 88\% (126/156) were male. The average age of the patients was 43.7 years (24 to 71 ). The mean follow-up was 78 months (11 to 276). Demographic data are shown in Table 2.

\section{SURGICAL TECHNIQUE}

All procedures were performed using a dorsal approach $^{4,12-14}$ except two studies: One used a volar approach in $4 / 41$ cases and lateral in $2 / 41$ cases, ${ }^{15}$ the second performed arthroscopic scaphoidectomy. ${ }^{7}$

Associated stiloidectomy was performed in four studies $^{4,12,13,15}$ for a total of $87 / 118$ (73\%) patients; two studies did not perform stiloidectomy, 7,16 and one ${ }^{13}$ performed the stiloidectomy, but the percentage was not reported. A dorsal capsulodesis was performed in two studies: eight of 39 patients (20\%) ${ }^{13}$ and in all patients $36 / 36 .^{12}$

\section{REHABILITATION}

All studies had their rehabilitation program with a variable lapse of immobilization time before starting mobilization. Five studies recommended three weeks wearing full time a spica splint before beginning rehabilitation of the wrist. 4,12,14-16 Aribert suggested a shorter immobilization of 2 weeks, while Gras et al. suggested an immediate ROM at home.

\section{OUTCOMES OF INTEREST}

\section{SUBJECTIVE AND OBJECTIVE OUTCOMES}

All subjective and objective outcomes are reported in Table 3. Four studies $7,13,14,16$ described postoperative pain using the VAS (Table 3). Daruwalla reported a median preoperative VAS of 81 , improving to 19 at eighteen months. The other three studies reported only the postoperative value with an average of 13.6 (range 7-22.3).

The Disability of Arm, Shoulder, and Hand score (DASH) or QDASH was evaluated in five studies. ${ }^{7,12-14,16}$ The me- 
Table 1

\begin{tabular}{|c|c|c|c|c|c|c|c|}
\hline & $\begin{array}{c}\text { Daruwalla } \\
\text { et al., } \\
2013\end{array}$ & $\begin{array}{l}\text { Aribert } \\
\text { et al., } \\
2019\end{array}$ & $\begin{array}{c}\text { Poumellec } \\
\text { et al., } \\
2019\end{array}$ & $\begin{array}{l}\text { Grandis } \\
\text { et al., } \\
2004\end{array}$ & $\begin{array}{c}\text { Pequignot } \\
\text { et al., } \\
2000\end{array}$ & $\begin{array}{l}\text { Gras } \\
\text { et al., } \\
2012\end{array}$ & $\begin{array}{c}\text { Santos } \\
\text { et al, } \\
2018\end{array}$ \\
\hline \multicolumn{8}{|c|}{ Part A: only one score to be given for each of the 6 sections } \\
\hline \multicolumn{8}{|c|}{ 1. Study size: number of patients } \\
\hline$<15$ & $x$ & & & & & $x$ & $x$ \\
\hline $15-24$ & & & $x$ & & & & \\
\hline $25-40$ & & $x$ & & & $x$ & & \\
\hline$>40$ & & & & $x$ & & & \\
\hline \multicolumn{8}{|c|}{ 2. Mean follow-up (months) } \\
\hline \multicolumn{8}{|l|}{$<35$} \\
\hline $36-71$ & $x$ & & & $x$ & & & \\
\hline $72-107$ & & & & & $x$ & $x$ & $x$ \\
\hline$>108$ & & $x$ & $x$ & & & & \\
\hline
\end{tabular}

\begin{tabular}{|c|c|c|c|c|c|c|c|}
\hline \multicolumn{8}{|l|}{ Not stated } \\
\hline \multicolumn{8}{|l|}{$\begin{array}{l}\text { Several techniques but } \\
\text { clearly stated }\end{array}$} \\
\hline $\begin{array}{l}>1 \text { technique but }>90 \% \\
\text { receiving one technique }\end{array}$ & & & & $\mathrm{x}$ & & & \\
\hline One technique & $x$ & $x$ & $x$ & & $x$ & $x$ & $x$ \\
\hline \multicolumn{8}{|l|}{ 4. Study type } \\
\hline \multicolumn{8}{|l|}{ Case report } \\
\hline Case series & $x$ & $x$ & $x$ & $x$ & $x$ & $x$ & $x$ \\
\hline \multicolumn{8}{|l|}{$\begin{array}{l}\text { Retrospective } \\
\text { comparative study }\end{array}$} \\
\hline \multicolumn{8}{|l|}{ Prospective cohort study } \\
\hline \multicolumn{8}{|l|}{$\begin{array}{l}\text { Randomized Control } \\
\text { Trials }\end{array}$} \\
\hline \multicolumn{8}{|c|}{ 4. Description of technique } \\
\hline \multicolumn{8}{|l|}{ Inadequate/not clear } \\
\hline \multicolumn{8}{|l|}{$\begin{array}{l}\text { Fair (technique only } \\
\text { stated) }\end{array}$} \\
\hline $\begin{array}{l}\text { Detailed (description of } \\
\text { materials used) }\end{array}$ & & $x$ & & & $x$ & & $x$ \\
\hline $\begin{array}{l}\text { Precise and details } \\
\text { (picture/diagrams) }\end{array}$ & $x$ & & $x$ & $x$ & & $x$ & \\
\hline
\end{tabular}

\section{Postoperative management/rehabilitation}

Not formalized

Yes but unclear

x

\begin{tabular}{|c|c|c|c|c|c|c|c|}
\hline Yes and clear & $\mathrm{x}$ & $\mathrm{x}$ & & & $\mathrm{x}$ & $\mathrm{x}$ & $\mathrm{x}$ \\
\hline \multicolumn{8}{|l|}{ 6. Complication discussed } \\
\hline \multicolumn{8}{|l|}{ Unclear/not mentioned } \\
\hline Mentioned but unclear & & & $\mathrm{x}$ & $\mathrm{x}$ & $\mathrm{x}$ & & $\mathrm{x}$ \\
\hline Fully discussed & $\mathrm{x}$ & $\mathrm{X}$ & & & & $\mathrm{x}$ & \\
\hline \multicolumn{8}{|c|}{ Part B: Scores may be given for each option in each of the 3 sections if applicable } \\
\hline \multicolumn{8}{|l|}{ 1. Outcome criteria } \\
\hline ROM & $\mathrm{x}$ & $\mathrm{X}$ & $\mathrm{x}$ & $x$ & $x$ & $x$ & $x$ \\
\hline Further procedure & & $x$ & $x$ & & $x$ & $x$ & \\
\hline VAS & $x$ & $x$ & $x$ & $x$ & $\mathrm{X}$ & $x$ & $x$ \\
\hline
\end{tabular}




\begin{tabular}{|c|c|c|c|c|c|c|c|}
\hline & $\begin{array}{c}\text { Daruwalla } \\
\text { et al., } \\
2013\end{array}$ & $\begin{array}{l}\text { Aribert } \\
\text { et al., } \\
2019 \\
\end{array}$ & $\begin{array}{c}\text { Poumellec } \\
\text { et al., } \\
2019\end{array}$ & $\begin{array}{l}\text { Grandis } \\
\text { et al., } \\
2004\end{array}$ & $\begin{array}{l}\text { Pequignot } \\
\text { et al., } \\
2000\end{array}$ & $\begin{array}{l}\text { Gras } \\
\text { et al., } \\
2012 \\
\end{array}$ & $\begin{array}{l}\text { Santos } \\
\text { et al, } \\
2018 \\
\end{array}$ \\
\hline Grip strength & $\mathrm{x}$ & $x$ & $x$ & $\mathrm{x}$ & $\mathrm{x}$ & $x$ & $\mathrm{x}$ \\
\hline Subjective scale & $x$ & $x$ & $x$ & & & $x$ & $x$ \\
\hline \multicolumn{8}{|c|}{ 2. Procedure of assessing outcome } \\
\hline $\mathrm{Rx}$ & $x$ & $\mathrm{x}$ & $x$ & $x$ & $x$ & $x$ & $x$ \\
\hline $\begin{array}{l}\text { Written assessment/ } \\
\text { questionnaire }\end{array}$ & & $x$ & $\mathrm{x}$ & & & $x$ & $x$ \\
\hline $\begin{array}{l}\text { Investigator independent } \\
\text { of the surgeon }\end{array}$ & & $\mathrm{x}$ & & & $x$ & & \\
\hline \multicolumn{8}{|c|}{ 3. Description of the subject selection process } \\
\hline MRI & & & & & & & $x$ \\
\hline Recruitment rate $>90 \%$ & $x$ & $x$ & $x$ & $x$ & $x$ & $x$ & \\
\hline Exclusion criteria clear & $x$ & & $x$ & & & & \\
\hline
\end{tabular}

\section{Table 2}

\begin{tabular}{|c|c|c|c|c|c|}
\hline Author & Journal & Patients (n) & Mean age & Female (\%) & Follow up (months) \\
\hline Daruwalla et al., 2013 & Ann Acad Med Singapore & 12 & $45 y$ & $16 \%$ & 18 \\
\hline Aribert et al., 2019 & Hand Surg Rehabil. & 33 & $42 y$ & $6 \%$ & 120 \\
\hline Poumellec et al., 2019 & J Wrist Surg. & 19 & $42 y$ & - & 132 \\
\hline Grandis et al., 2004 & Riv Chir Mano & 41 & $40 y$ & $14 \%$ & 36 \\
\hline Pequignot et al., 2000 & Chir Main. & 25 & $46 y$ & $4 \%$ & 72 \\
\hline Gras et al., 2012 & J Wrist Surg. & 14 & $52,7 y$ & $0 \%$ & 104 \\
\hline Lima Santos et al., 2018 & Rev Bras Ortop. & 12 & $39 y$ & $0 \%$ & 66 \\
\hline
\end{tabular}

dian postoperative DASH was 19.6 (range 7.6-26). The Mayo wrist score was evaluated in four studies $7,12,13,16$ with a median value of 74 (range 67,5-80).

All the studies measured the flexion-extension arch with an average value of $114^{\circ}$ (range $71^{\circ}-136^{\circ}$ ). The grip strength was evaluated in six studies..$^{4,7,12-15}$

\section{RETURN TO WORK}

Daruwalla et al. reported a return to work at an average of eleven weeks; Aribert et al. reported that 23/24 returned to their previous job at an average time of 2.1 months. Santos et al. reported that all patients returned to their previous job. Pequignot et al. reported that $22 / 25$ (88\%) patients returned to their previous job. Three studies did not report any information regarding return to work: Grandis et al., Poumellec et al., and Gras et al. (Table 3)

\section{CARPAL MISALIGNMENTS}

One study ${ }^{13}$ reported the presence of DISI in $46.3 \%$ of patients. One study ${ }^{4}$ did not report any changes in the SL angle. One study ${ }^{12}$ reported changes in the SL angle in 9/19 patients (47\%). Gras et al. reported a correction of the dorsal intercalated segmental instability (DISI) in $5 / 8$ patients (62.5\%) after surgery. (Table 4)

\section{PROGRESSION OF OSTEOARTHRITIS}

One study ${ }^{13}$ reported a progression of osteoarthritis in 6/ 33 patients (18\%). Poumellec et al. report a progression of the OA in 6/19 of patients (32\%). Gras et al. reported a radial stiloidectomy 2-3 years after the APSI procedure in 3/ 14 patients (21\%) for radio-scaphoid arthritis progression. Santos et al. reported OA progression in all the cases (12/ 12). Three studies ${ }^{4,14,15}$ did not report any OA progression. The percentage of patients who reported progression of OA was $17.3 \%(27 / 156$; Table 4$)$.

\section{COMPLICATIONS}

Four studies reported no complication, ${ }^{4,14-16}$ Gras et al. reported two mobilizations of the implant treated with a 4CF. Poumellec et al. reported two cases of early implant dislocations due to a lack of compliance to the postoperative immobilization required.

Aribert et al. described 6/33 complications (18\%). One case of early sepsis required implant removal, four instances of dislocation, and one patient complained about persistent pain caused by radio-scaphoid impingement and was treated with a 4CF. The total amount of mobilization of the implant was $5.1 \%(8 / 156$; Table 4$)$. 
Table 3

\begin{tabular}{|c|c|c|c|c|c|c|c|c|c|c|c|c|c|}
\hline \multirow[t]{2}{*}{ Author } & \multirow[t]{2}{*}{$\begin{array}{l}\text { Return to } \\
\text { work }\end{array}$} & \multicolumn{2}{|c|}{ DASH } & \multicolumn{2}{|c|}{ MWS } & \multicolumn{2}{|c|}{ POWER } & \multicolumn{2}{|c|}{ VAS } & \multicolumn{2}{|c|}{ Grip strength } & \multicolumn{2}{|c|}{ ROM } \\
\hline & & $\begin{array}{l}\text { Pre } \\
\text { op }\end{array}$ & $\begin{array}{l}\text { Post } \\
\text { op }\end{array}$ & $\begin{array}{l}\text { Pre } \\
\text { op }\end{array}$ & $\begin{array}{l}\text { Post } \\
\text { op }\end{array}$ & $\begin{array}{l}\text { Pre } \\
\text { op }\end{array}$ & $\begin{array}{l}\text { Post } \\
\text { op }\end{array}$ & Pre op & Post op & $\begin{array}{l}\text { Pre } \\
\text { op }\end{array}$ & Post op & $\begin{array}{l}\text { Pre } \\
\text { op }\end{array}$ & $\begin{array}{l}\text { Post } \\
\text { op }\end{array}$ \\
\hline $\begin{array}{l}\text { Daruwalla et } \\
\text { al. }\end{array}$ & $11 w$ & 55 & 20 & & & & & $\begin{array}{c}81 \\
(0-100)\end{array}$ & $\begin{array}{c}19 \\
(0-100)\end{array}$ & $30 \mathrm{~kg}$ & $30 \mathrm{~kg}$ & $73^{\circ}$ & $80^{\circ}$ \\
\hline Aribert et al. & $8 w$ & - & 19.5 & - & 80 & - & 17.5 & - & $\begin{array}{c}1.2 \\
(0-10)\end{array}$ & $27 \mathrm{~kg}$ & $38 \mathrm{~kg}$ & $99^{\circ}$ & $101^{\circ}$ \\
\hline $\begin{array}{l}\text { Poumellec et } \\
\text { al. }\end{array}$ & - & - & 26 & - & 69 & - & 25 & - & - & - & $34 \mathrm{~kg}$ & - & $106^{\circ}$ \\
\hline Grandis et al. & - & & & & & & & & & - & $\begin{array}{c}40 \% \text { of } \\
\text { improvement }\end{array}$ & - & $100^{\circ}$ \\
\hline $\begin{array}{l}\text { Pequignot et } \\
\text { al. }\end{array}$ & - & & & & & & & & & - & $\begin{array}{c}80 \% \text { of } \\
\text { controlateral }\end{array}$ & - & $95^{\circ}$ \\
\hline Gras et al. & - & - & 7.6 & - & 79.6 & & & $\begin{array}{c}7.5 \\
(0-10)\end{array}$ & $\begin{array}{c}0.7 \\
(0-10)\end{array}$ & $\begin{array}{c}15.8 \\
\mathrm{~kg}\end{array}$ & $44.1 \mathrm{~kg}$ & $77^{\circ}$ & $136^{\circ}$ \\
\hline $\begin{array}{l}\text { Lima Santos et } \\
\text { al. }\end{array}$ & - & - & 25 & - & 67.5 & - & - & - & $\begin{array}{c}22.3 \\
(0-100)\end{array}$ & - & - & - & $71^{\circ}$ \\
\hline
\end{tabular}

Table 4

\begin{tabular}{cccc}
\hline Authors & Numbers of patients & Osteoarthritis progression & Malalignment \\
\hline Daruwalla et al & 12 & & Complications \\
Aribert et al. & 33 & 6 & $41.6 \%$ of DISI \\
Poumellec et al. & 19 & 6 & $47 \%$ of DISI \\
Grandis et al & 41 & & 1 infecations \\
Pequignot et al. & 25 & 3 & 2 dislocations \\
Gras et al. & 14 & 12 & $8 \%$ of DISI \\
Lima Santos et al. & 12 & dislocations & \\
\hline
\end{tabular}




\section{DISCUSSION}

Some of the most widely used treatment options for wrist pain include PRC and 4CF. A systematic review in $2009^{3}$ compared these two techniques and found no differences in terms of pain, grip strength, and subjective outcome. These data suggest that PRC has fewer potential complications and better ROM than $4 \mathrm{CF}$ but a higher risk of progression of OA. Some researchers have tried to replace the scaphoid with interposition of autologous material, ${ }^{17,18}$ silicon, ${ }^{19}$ or metal, ${ }^{20}$ but the results were not satisfactory.

The average quality of the studies included in the present investigation is moderate, with an average CMS of 60 points; only one study ${ }^{13}$ had good CMS values. The most common surgical approach was from the dorsal wrist except for two studies that adopted an arthroscopic approach. 7,15 Arthroscopy is an attractive option for its minimally invasive procedure and consequent preservation of soft tissues, including ligaments and capsules.

Stiloidectomy is widely performed ${ }^{4,12-15}$ (73\% of all patients) and is advisable in the case of a stylo-carpal impingement. Two papers ${ }^{12,13}$ performed a dorsal capsulodesis with no improvement in implant stability. There were six dislocations of the implant out of eight in these studies. All studies reported a postoperative immobilization of 2-3 weeks except for one, ${ }^{7}$ which allowed an early ROM probably due to the low invasiveness of the arthroscopic procedure.

All the studies described a reduction in grip strength and the flexion-extension arch compared to the contralateral wrist but with improvement versus preoperative values. The highest value in flexion-extension $\operatorname{arch}\left(136^{\circ}\right.$ vs. an average value of $92^{\circ}$ ) and grip strength $(44.1 \mathrm{~kg}$ vs. an average value of $34 \mathrm{~kg}$ ) were reported by Gras et al., who performed the replacement arthroscopically and with an early rehabilitation protocol. The same study ${ }^{7}$ reported the best score in subjective outcomes such as DASH and VAS. We hypothesize that this is due to less scar tissue and a more aggressive rehabilitation protocol.

Gras et al. reported a correction of the dorsal intercalated segmental instability (DISI) in $5 / 8$ patients $(62.5 \%)$ after surgery. The role of the APSI is controversial in its impact on the DISI deformity: two studies ${ }^{12,13}$ reported an increased SL angle in $46 \%$ of patients despite the use of capsulodesis. We speculated that the arthroscopic approach preserves the secondary stabilizer versus the open technique.

The percentage of patients who reported progression of OA with APSI was $17.3 \%$, the average increases to $26 \%$ (27/ 103) if we consider only studies with more than five years in the follow-up: Aribert et al., Poumellec et al. Pequignot et al., Gras et al. Santos et al. The APSI slowed the progression of OA but did not stop it. The implant mobilization has a rate of $5.1 \%(8 / 156)$. The surgical approach and postoperative immobilization does not correlate with this value. In one series, ${ }^{7}$ the use of the implant for a nonunion of the body of the scaphoid leads to mobilization.

All procedures were performed using a dorsal approach $^{4,12-14,16}$ except two studies: One used a volar approach in $4 / 41$ cases and lateral in $2 / 41$ cases, 15 the second performed arthroscopic scaphoidectomy. ${ }^{7}$ Associated stiloidectomy was performed in four studies $4,12,13,15$ for a total of $87 / 118$ (73\%) patients; two studies did not perform stiloidectomy, ${ }^{7,16}$ and one ${ }^{14}$ performed the stiloidectomy, but the percentage was not reported. A dorsal capsulodesis was performed in two studies-eight of 39 patients (20\%) ${ }^{13}$ and all patients $36 / 36$. $^{12}$

All studies had their rehabilitation program with a variable lapse of immobilization time before starting mobilization. Five studies recommended three weeks wearing full time a spica splint before beginning rehabilitation of the wrist. ${ }^{4,12,14-16}$ Aribert suggested a shorter immobilization of 2 weeks, while Gras et al. suggested an immediate ROM at home.

The study has several limitations. For example, we grouped different cohorts of patients in terms of demographics, surgical indication, surgical technique, outcome measurements, and follow-up.

The main endpoint of this systematic review is that the APSI implant is a reliable alternative for treating SNAC wrist and SLAC wrist. Its indications are limited: The cartilage of the scaphoid fossa and the capitolunate joint must be intact. However, the implants require less surgical dissection compared to $4 \mathrm{CF}$ and $\mathrm{PRC}$. This procedure is more expensive than 4CF and PRC due to the high cost of the spacer, but further surgeries are possible in case of failure.

Submitted: November 19, 2021 EDT, Accepted: December 03, 2021 EDT 


\section{REFERENCES}

1. Watson HK, Ballet FL. The SLAC wrist:

Scapholunate advanced collapse pattern of degenerative arthritis. J Hand Surg Am. 1984;9(3):358-365. doi:10.1016/s0363-5023(84)8022 3-3

2. Laulan J, Marteau E, Bacle G. Wrist osteoarthritis. Orthop Traumatol Surg Res. 2015;101(1):S1-S9. doi:1 $\underline{0.1016 / j . o t s r .2014 .06 .025}$

3. Mulford JS, Ceulemans LJ, Nam D, Axelrod TS. Proximal row carpectomy vs. four-corner fusion for scapholunate (SLAC) or scaphoid nonunion advanced collapse (SNAC) wrists: a systematic review of outcomes. J Hand Surg Eur Vol. 2009;34(2):256-263. 며 oi:10.1177/1753193408100954

4. Pequignot JR, Lussiez B, Allieu Y. Implant adaptatif du scaphoïde proximal. Chir Main. 2000;19(5):276-285. doi:10.1016/s1297-3203(00)7349 $\underline{2-5}$

5. Mariconda M, Russo S, Smeraglia F, Busco G. Partial trapeziectomy and pyrocarbon interpositional arthroplasty for trapeziometacarpal joint osteoarthritis: Results after minimum 2 years of follow-up. J Hand Surg Eur Vol. 2014;39(6):604-610. $\underline{\mathrm{d}}$ oi:10.1177/1753193413519384

6. Smeraglia F, Barrera-Ochoa S, Mendez-Sanchez G, Basso MA, Balato G, Mir-Bullo X. Partial trapeziectomy and pyrocarbon interpositional arthroplasty for trapeziometacarpal osteoarthritis: minimum 8-year follow-up. J Hand Surg Eur Vol. 2020;45(5):472-476. doi:10.1177/1753193420906805

7. Gras M, Wahegaonkar A, Mathoulin C. Treatment of avascular necrosis of the proximal pole of the scaphoid by arthroscopic resection and prosthetic semi replacement arthroplasty using the pyrocarbon adaptive proximal scaphoid implant (APSI): longterm functional outcomes. J Wrist Surg. 2012;01(02):159-164. doi:10.1055/s-0032-1329591

8. Moher D, Liberati A, Tetzlaff J, Altman DG. Preferred reporting items for systematic reviews and meta-analyses: The PRISMA statement. PLoS Med. 2009;6(7):e1000097. doi:10.1371/journal.pmed.10000 $\underline{97}$

9. Coleman BD, Khan KM, Maffulli N, Cook JL, Wark JD. Studies of surgical outcome after patellar tendinopathy: Clinical significance of methodological deficiencies and guidelines for future studies. Scand $J$ Med Sci Sport. 2000;10(1):2-11. doi:10.1034/j.1600-08 38.2000.010001002.x
10. Smeraglia F, Del Buono A, Maffulli N. Collagenase clostridium histolyticum in Dupuytren's contracture: a systematic review. Br Med Bull.

2016;118(1):149-158. doi:10.1093/bmb/ldw020

11. Smeraglia F, Basso MA, Famiglietti G, Eckersley R, Bernasconi A, Balato G. Partial wrist denervation versus total wrist denervation: a systematic review of the literature. Hand Surg Rehabil. 2020;39(6):487-491. doi:10.1016/i.hansur.2020.05.010

12. Poumellec MA, Camuzard O, Pequignot JP, Dreant N. Adaptive Proximal Scaphoid Implant: Indications and Long-Term Results. J Wrist Surg. 2019;08(04):344-350. doi:10.1055/s-0039-1681034

13. Aribert M, Bouju Y, Chaise F, Loubersac T, Gaisne $\mathrm{E}$, Bellemère $\mathrm{P}$. Adaptive proximal scaphoid implant (APSI): 10-year outcomes in patients with SNAC wrists. Hand Surg Rehabil. 2019;38(1):34-43. doi:10.1 016/j.hansur.2018.10.245

14. Daruwalla ZJ, Davies KL, Shafighian A, Gillham NR. An alternative treatment option for scaphoid nonunion advanced collapse (SNAC) and radioscaphoid osteoarthritis: Early prospective study results on the pyrocarbon adaptive proximal scaphoid implant (APSI). Ann Acad Med Singapore.

2013;42:278-284.

15. Grandis C, Berzero GF, Bassi F, Allieu Y. Prime esperienze di utilizzo in Italia della protesi parziale di scafoide APSI. Riv Chir Mano. 2004;41:36-42.

16. Santos FL, Ferreira A, Grazina R, Sá D, Canela P, Lemos R. APSI scaphoid hemiarthroplasty - longterm results. Rev Bras Ortop. 2018;53(5):582-588. do $\underline{\mathrm{i}: 10.1016 / \mathrm{i} . \mathrm{rboe} .2018 .07 .011}$

17. Garcia-Elias M, Lluch A. Partial excision of scaphoid: Is it ever indicated? Hand Clin.

2001;17(4):687-695. doi:10.1016/s0749-0712(21)0145 $\underline{2-9}$

18. Smeraglia F, Ciaramella G, Cerbasi S, Balato G, Mariconda M. Treatment of proximal scaphoid nonunion by resection of the proximal pole and palmaris longus interposition arthroplasty. Handchir Mikrochir Plast Chir. 2015;47(03):171-174. doi:10.105 5/s-0035-1548847

19. Egloff DV, Varadi G, Narakas A, Simonetta C, Cantero C. Silastic implants of the scaphoid and lunate: A long-term clinical study with a mean follow-up of 13 years. J Hand Surg Br. 1993;18(6):687-692. doi:10.1016/0266-7681(93)9022 $\underline{3-3}$ 
20. Slutsky DJ. Unconstrained pyrolytic carbon (Pyrocarbon) spacers in wrist surgery. In: Principles and Practice of Wrist Surgery. Saunders Elsevier; 2010:266-276. https://doi.org/10.1016/b978-1-4160-5 646-1.00023-0 